\title{
Effect of the Type of Ultraviolet on the Photocatalytic Removal of Xylene as a Pollutant in the Air Using $\mathrm{TiO}_{2}$ Nanoparticles Fixed on the Activated Carbon
}

\author{
Hossein Ali Rangkooy', Fereshteh Jahani, Atefeh Siahi Ahangar ${ }^{2, *}$ \\ ${ }^{I}$ Assistant Professor, Environmental Technologies Research Center, Ahvaz Jundishapur University of Medical Sciences, \\ Ahvaz, Iran \\ ${ }^{2}$ MSc Student, Department of Occupational Health Engineering, School of Health, Ahvaz Jundishapur University of Medical \\ Sciences, Ahvaz, Iran \\ * Corresponding Author: Atefeh Siahi Ahangar, Department of Occupational Health Engineering, School of Health, Ahvaz \\ Jundishapur University of Medical Sciences, Ahvaz, Iran. Email: siahi2068@ gmail.com
}

\begin{abstract}
Received: 18/01/2019

Background and Objective: Currently, photocatalysts have become a major Accepted: 23/02/2019 focus of research in physics, chemistry, and surface engineering. It is hoped that this science help to solve various environmental problems. This study

How to Cite this Article:

Rangkooy HA, Jahani F, Siahi Ahangar A. Effect of the Type of Ultraviolet on the Photocatalytic Removal of Xylene as a Pollutant in the Air Using $\mathrm{TiO}_{2}$ Nanoparticles Fixed on the Activated Carbon. J Occup Hyg Eng. 2019; 5(4): 26-32. DOI: 10.29252/johe.5.4.26 investigated the effect of ultraviolet lamp type on the removal efficiency of xylene utilizing the fixation of $\mathrm{TiO}_{2}$ nanoparticles on the activated carbon absorber and passing different concentrations of polluted air through xylene.

Materials and Methods: In this experimental study, after the fixation of nanoparticles on activated carbon, the produced catalyst characteristics with the specific surface area were determined using Brunauer-EmmettTeller (BET) analysis and scanning electron microscope (SEM). A dynamic concentrator system was used in order to produce xylene vapor. Moreover, the photocatalytic removal efficiency of xylene with three inlet concentrations of the pollutant was studied under ultraviolet rays in the wavelengths of $A$ and $C$ regions.

Results: The results of BET analysis and SEM images showed that nanoparticles were well fixed on the surface of activated carbon. Moreover, the photocatalytic removal efficiency in the concentrations of 50, 100 and $300 \mathrm{ppm}$ was equal to $87.8 \%, 98.9 \%$, and $90.8 \%$, respectively. In addition, no significant difference was observed between ultraviolet $A$ and $C$ regarding photocatalytic removal efficiency of xylene.

Conclusion: According to the results of this study, the inlet concentration of the pollutant had an effect on its photocatalytic removal efficiency. However, there was no significant difference between ultraviolet $A$ and $C$ regarding photocatalytic removal efficiency of xylene.
\end{abstract}

Keywords: Photocatalytic Removal; $\mathrm{TiO}_{2}$ Nanoparticles; Ultraviolet A; Ultraviolet $C$ 


\section{بررسى تأثير نوع اشعه فرابنفش در كارايى حذف فتو كاتاليستى آلاينده زايلن در هوا توسط نانوذر ات}

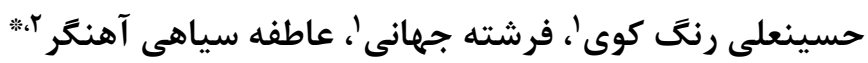

' استاديار، كروه مهندسى بهداشت حرفهاى، دانشكده بهداشت، دانشعاه علوم يزشكى جندى شايور اهواز، اهواز، ايران

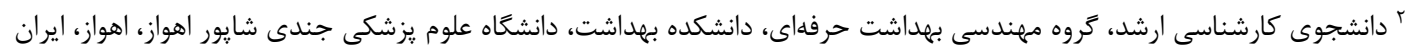
* نويسنده مسئول: عاطفه سياهى آهنخر، گروه مهندسى بهداشت حرفهاى، مهندسى بهداشت حرفهاى، دانشكده بهداشت، دانشعاه علوم بزشكى جندى شايور اهواز، اهواز، ايران. ايميل: siahi2068@gmail.com

\section{جكيده}

سابقه و هدف: امروزه فتوكاتاليست بخش عمدهاى از تحقيقات در حوزههاى علمى از قبيل فيزيك، شيمى و

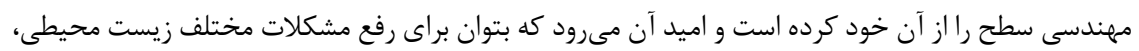

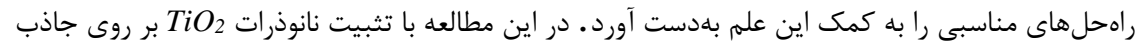

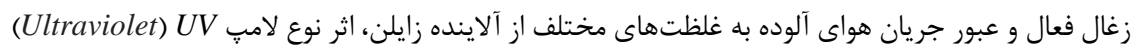

$$
\text { بر كارايى حذف زايلن مورد بررسى قرار گرفت فوران. }
$$

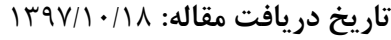

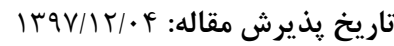
تمامى حقوق نشر براى دانشكاه علوم يزشكى همدان محفوظ است.

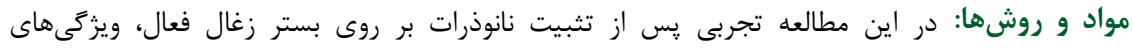

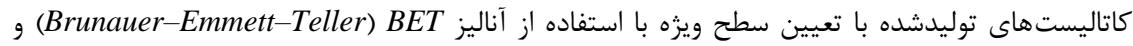

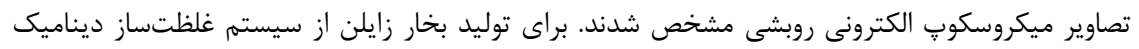

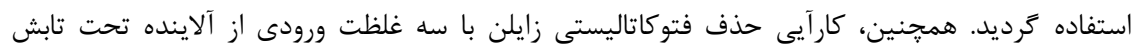

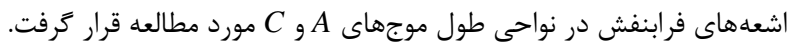

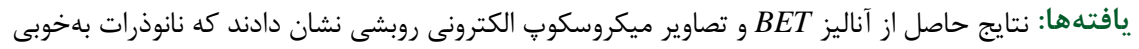

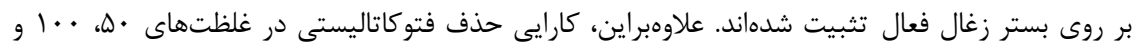

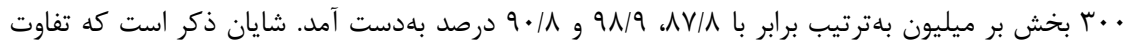
معنادارى در كارايى حذف فتو كاتاليستى زايلن تحت تابش اشعه بـ

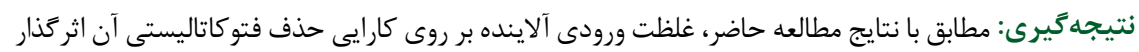

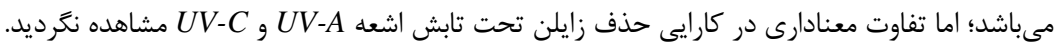

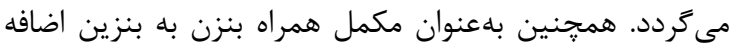

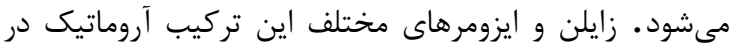

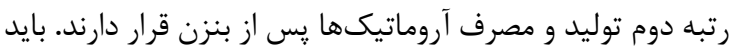

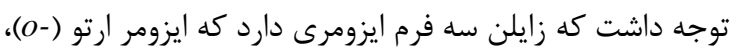

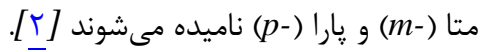

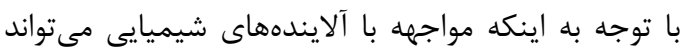

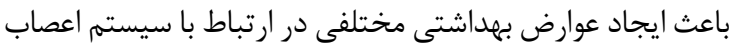

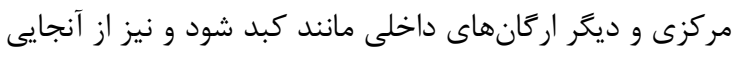

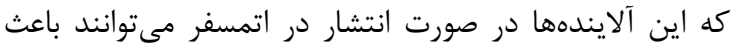

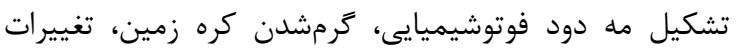
آب و هوايى و ديگر مشكلات محيط زيستى گردند، تدوين دوني
مقدمه آلايندهاى مهرم شيميايى آلى موجود در مجتمعهاى

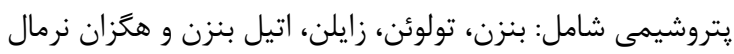

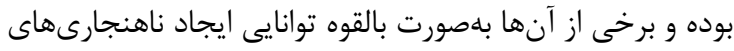

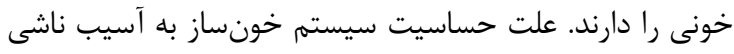

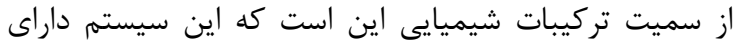

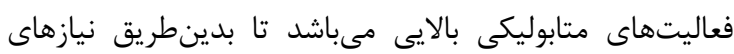

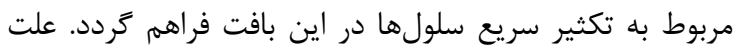

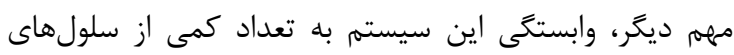
بنيادى با فعاليت تكثيرى محدود مىباشد [ [1].

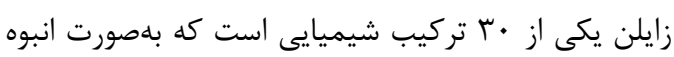
توليد مىشود و در صنايع مختلف از تركيبات آن استفاده 
بررسى قرار گرفت.

\section{مواد و روشها}

مطالعه تجربى حاضر در مقياس آزمايشعاهى انجام شد. ابتدا

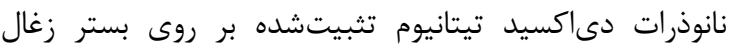

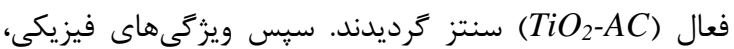
مورفولوزى سطح و قابليت آنها در تجزيه و حذف زايلن در فاز گازى تحت تابش اشعه فرابنفش بررسى شدند.

\section{تثبيت نانوذرات بر روى بستر زغال فعال}

در اين يزوهش براى بررسى درصد بهينه، نانوذرات

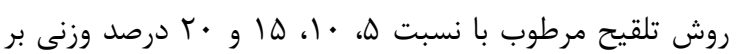
روى بستر زغال فعال تثبيت شدند. مقدار مناسب از هر نانوذره

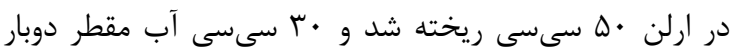

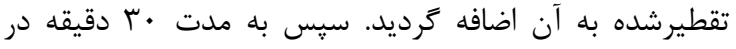

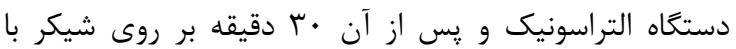

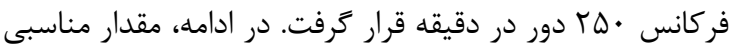

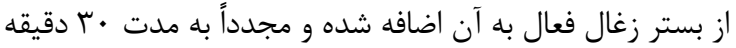

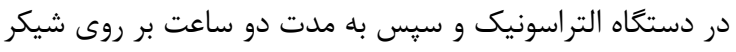

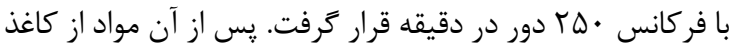

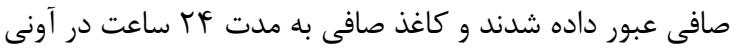

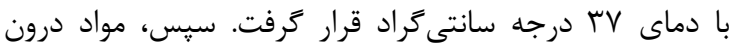

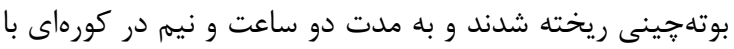

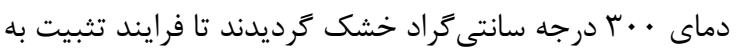

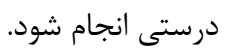

\section{تعيين مشخصات فتوكاتاليست}

براى تعيين مساحت سطحى و سايز حفرات از دستگاه آناليزور مساحت سطحى Quantachrome Chem BET با جريان كاز نيتروزن استفاده گرديد. در اين روش با با اندازهگيرى فشار كاز

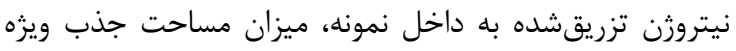

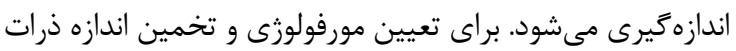

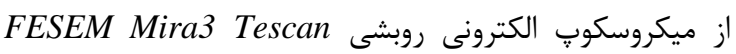
با ولتاز شتابدهنده ها كيلوولت استفاده كرديد.

\section{سيستهم راكتور فوتوكاتاليستى}

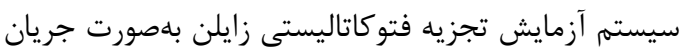

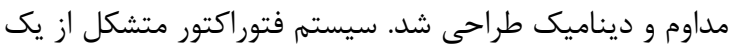

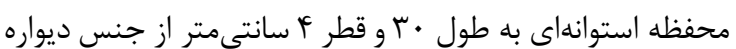

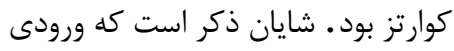

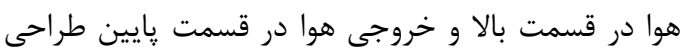

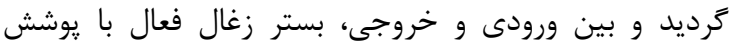
نانوذرات

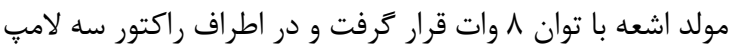

استراتزىهايى براى كاهش بخارات شيميايى مسأله بسيار مهمى

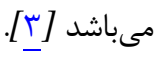

يكى از مههمترين و متداولترين روشهاى روش مورد استفاده

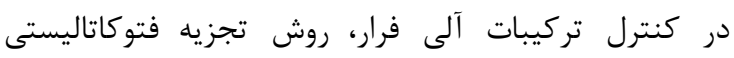

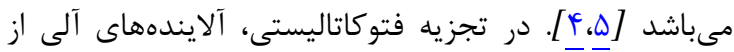

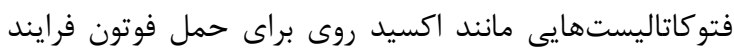

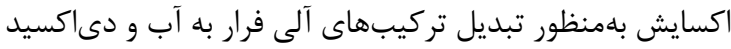

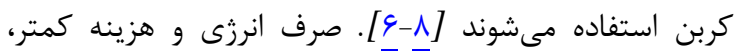

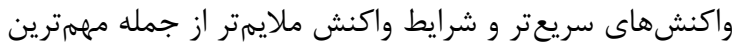

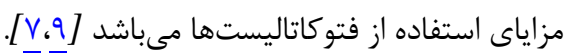

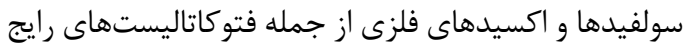
مىباشند كه از جمله آنها مىتوان به فئ فوتوكاتاليستها TiO با فوتونهاى يرانرزى در نتيجه ترك حفرههاى الكترونى

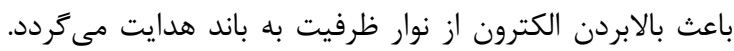

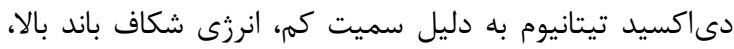

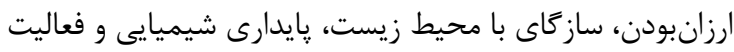

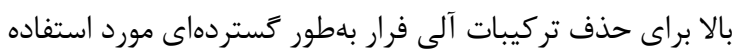

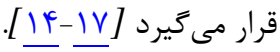

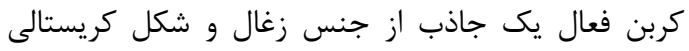
مىباشد كه در ساختار داخلى آن روزنههاى زيادى وجنى وجود دادي دارد.

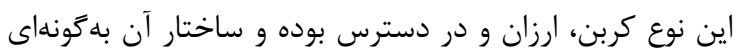

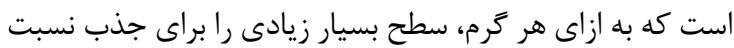

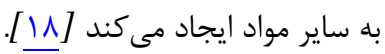

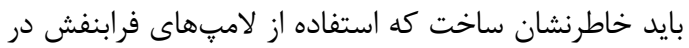

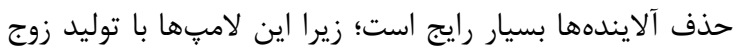

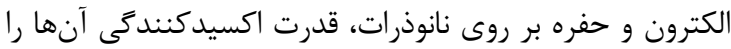
افزايش مى دهند كه به آن "سيستم تجزيه نورى" كفتته مى شودود

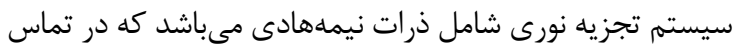

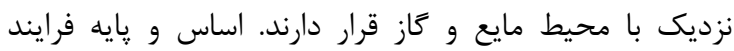

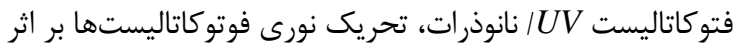

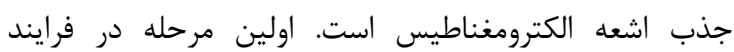
فتو كاتاليتيك، جذب اشعه UV در سطح نانوذرات همراه با تشكيل

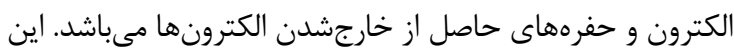

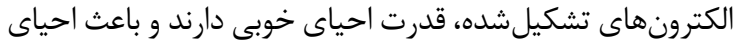

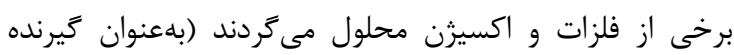

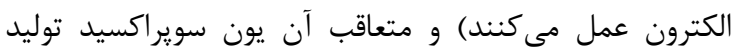

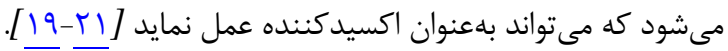

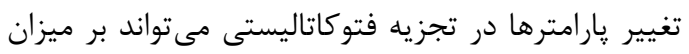

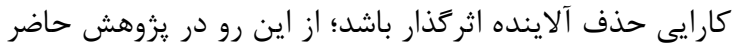
با تثبيت نانوذرات هواى آلوده با غلظتهاى مختلف از زايلن تحت تابش لامب

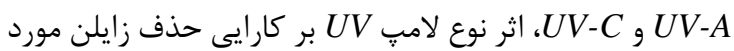


آزمايشات حذف فتوكاتاليستى را نشان مىدهد. اندازهيرى بخارات زايلن نيز با استفاده از دستخاه قرائت مستقيم (مدل Phocheck Tiger يونش نورى (PID: Photoionization Detector) انجام شد و ميزان كارايى حذف با توجه به رابطه زير محاسبه گرديد: $X=\left(C_{i}-C_{o} / C_{i}\right) \times 1 \cdots$

در اين رابطه X كارايى تجزيه فتوكاتاليستى زايلن بر حسب

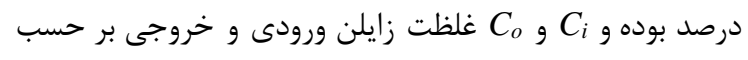
ميلى

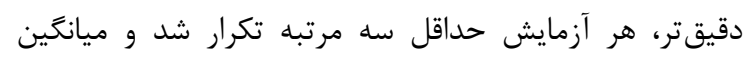
اندازهيرىها يس از ثبت در هرئ جداول اوليه مورد استفاده قرار

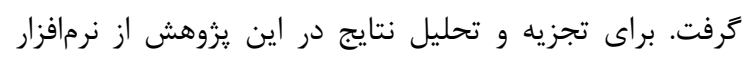
SPSS 24
فرابنفش با توان 9 وات قرار داده شد. جهت جلوَيرى از اتلاف

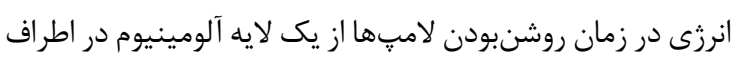

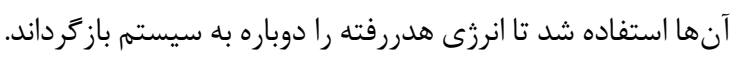

\section{حذف فتوكاتاليستى} يس از تهيه غلظت لازم از زايلن و ثابت نگَدداشتن جريان كلى

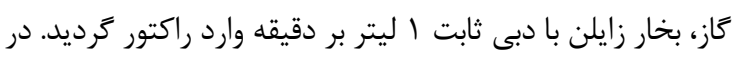

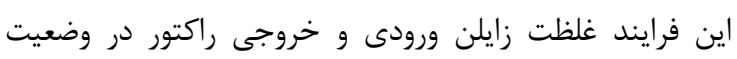

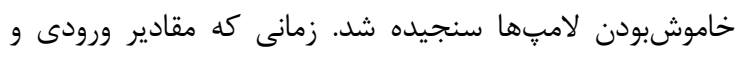

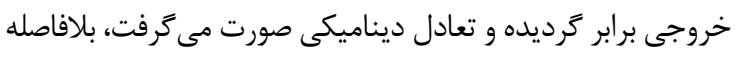

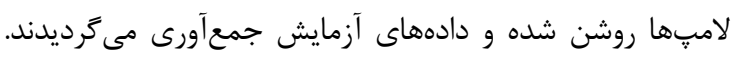

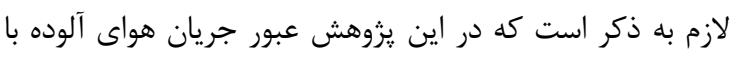

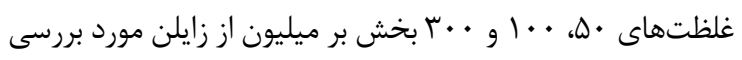

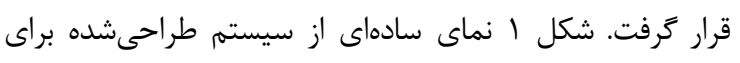

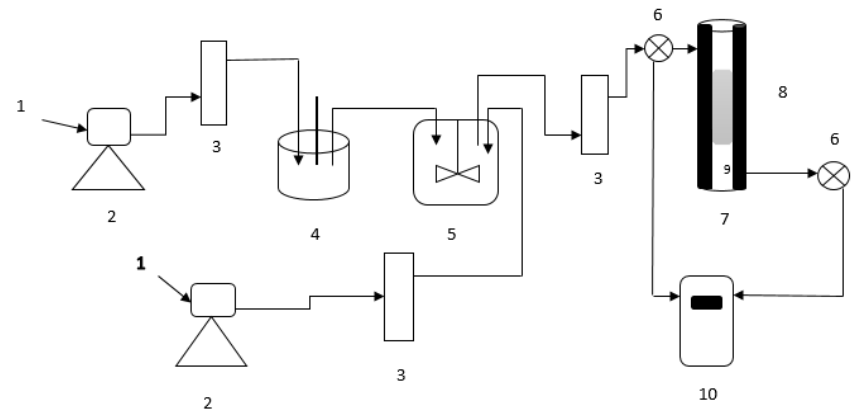

شكل ا: نماى سادهاى از سيستم طراحىشده براى آزمايشات حذف فتوكاتاليستى

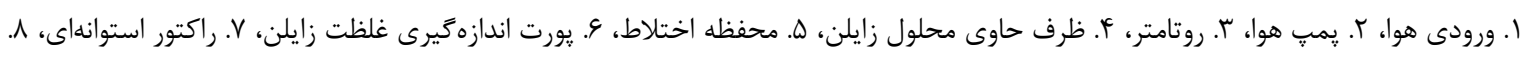

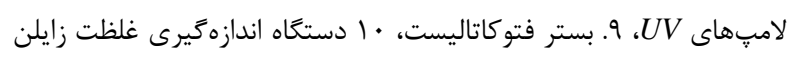

\section{يافتهها}

داده شد. نتايج تجزيه زايلن توسط فتوكاتاليستهاى

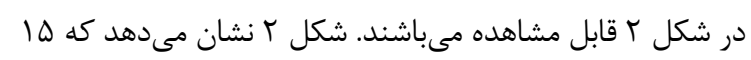
درصد وزنى از نانوذرات دiO

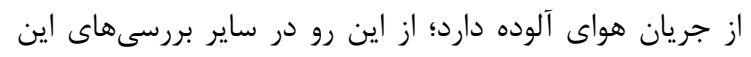
يزوهش از TiO براى بررسى تأثير غلظت زايلن ورودى به سيستم در هر

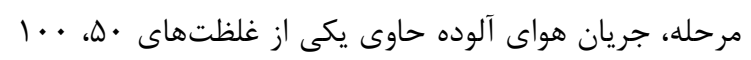

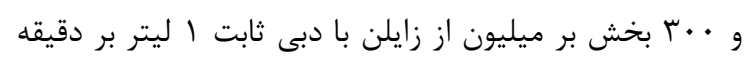

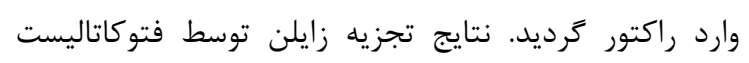
TiO $\mathrm{TiO}_{2}-85 A C$

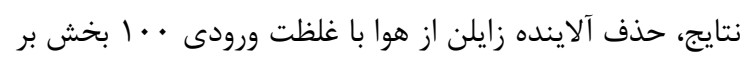

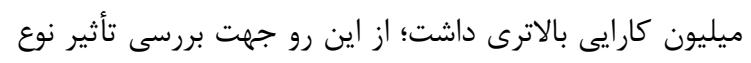

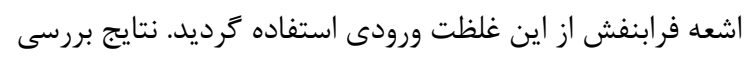

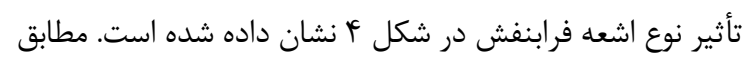

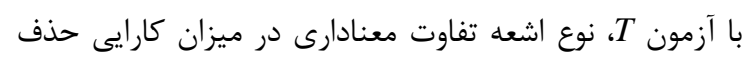

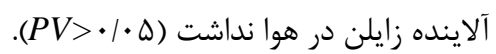

\section{ويزگحىهاى ساختارى بستر}

در اين بررسى ويزگى مساحت سطح ويزه (BET) AC/TiO و بهترتيب برابر با (AC: Active Cole)

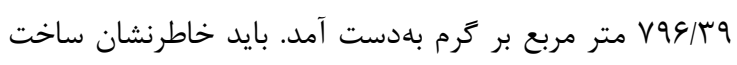

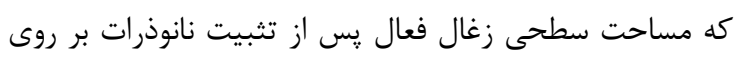

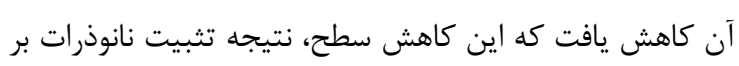

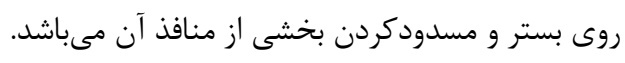

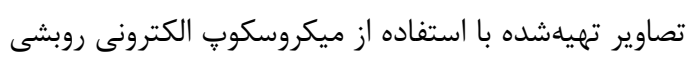
در شكل ا ارائه (SEM: Scanning Electron Microscope) شدهاند. اين تصاوير نشان مىدهند كه نانوذرات بهصورت تودهاى : خلى بر روى خلل و فرج بستر زغال فعال قرار گرفتهاند. سطوح ناهموار بستر و حفرات بهخوبى در اين تصاوير قابل مشاهده هستند.

براى تعيين كارايى حذف زايلن از جريان هوالى آلوده در هر

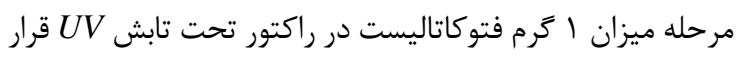




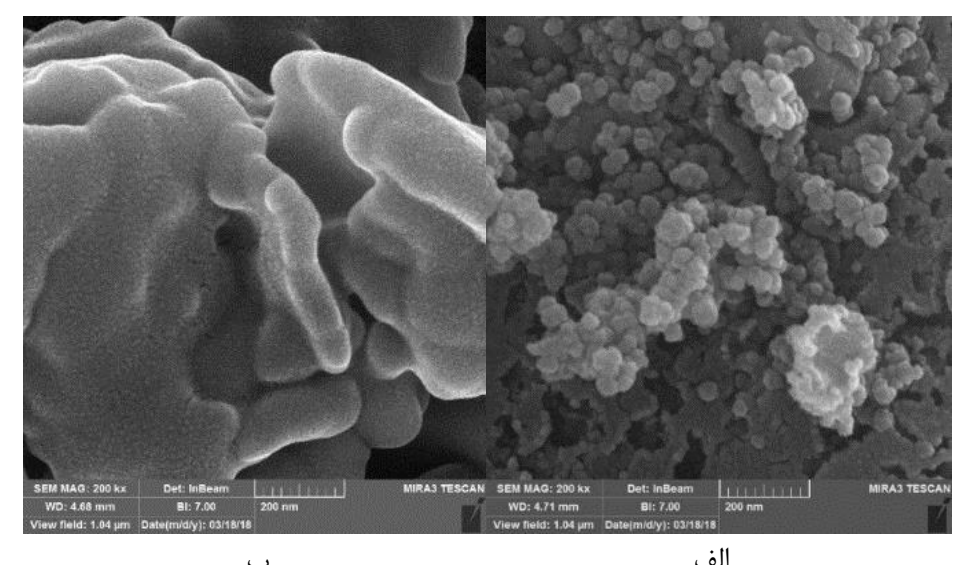

الف

شكل ا: تصاوير FESEM: الف. AC؛ ب. AC/TiO

$\mathrm{AC} / \mathrm{TiO} 2$

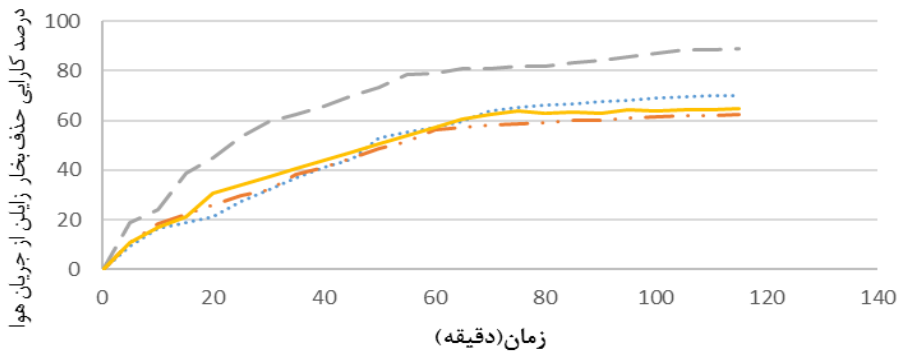

$\mathrm{AC} / \mathrm{TiO} 25 \%-\cdots \mathrm{AC} / \mathrm{TiO} 210 \%-\mathrm{AC} / \mathrm{TiO} 215 \%-\mathrm{AC} / \mathrm{TiO} 220 \%$ شكل r: كارايى حذف زايلن در نسبتهاى مختلف از AC/TiO

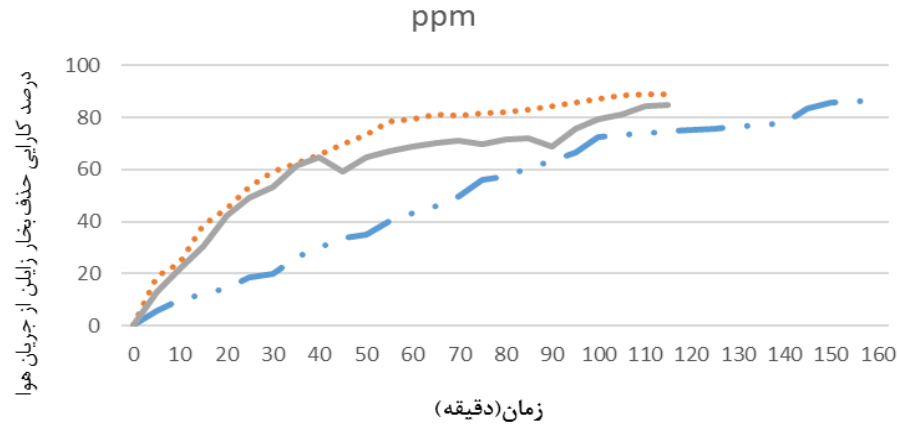

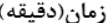

-50ppm $\cdots 100 \mathrm{ppm}-300 \mathrm{ppm}$

شكل r: تأثير غلظت زايلن ورودى بر كارايى حذف فتوكاتاليستى

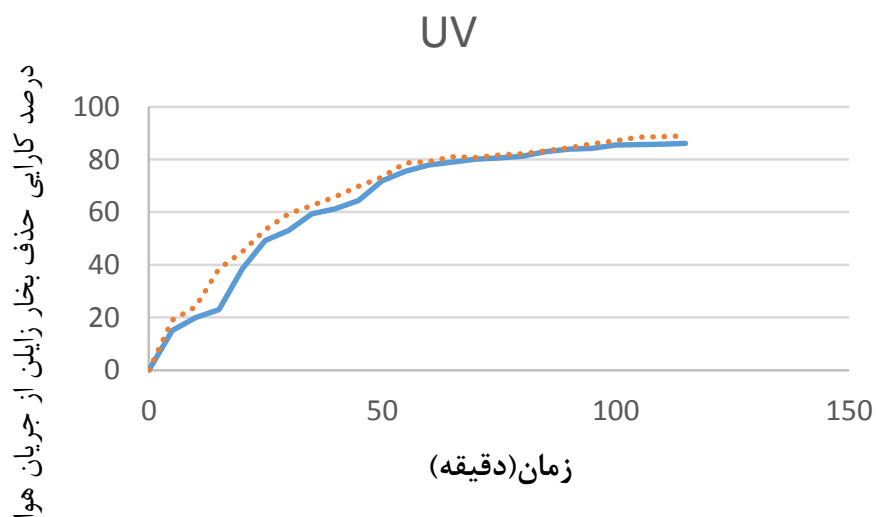




$$
\text { شكل Fا: تأثير نوع اشعه فرابنفش بر كارايى حذف زايلن }
$$

UV/ZnO-95BC

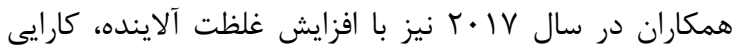

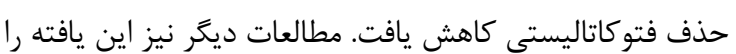
تأييد مى كنند [TV-YV] بر مبناى نتايج اين مطالعه، حذف فتوكاتاليستى زايلن تحت

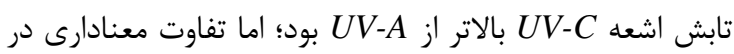
كارايى حذف فتوكاتاليستى زايلن تحت تابش اشعه الاني إن

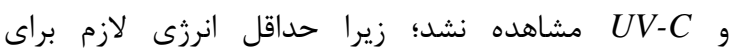

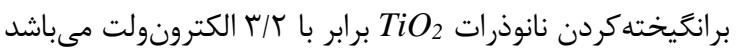

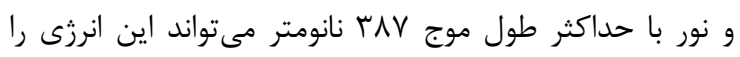

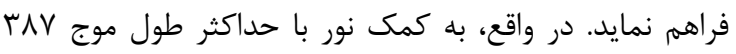

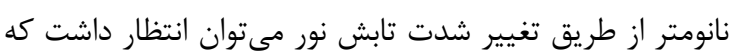

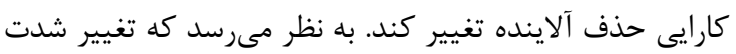

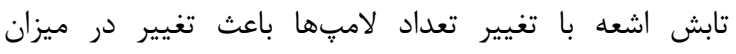

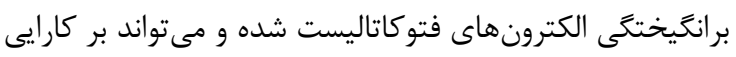

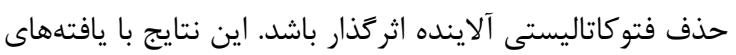

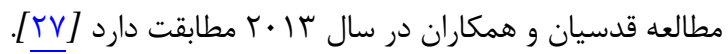

\section{نتيجه كيرى}

نتايج بلهدستآمده از اين مطالعه نشان دادند كه غلظت

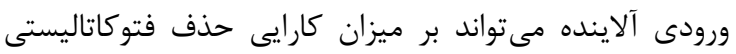

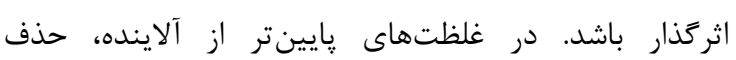

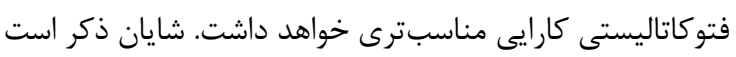

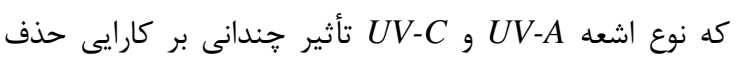

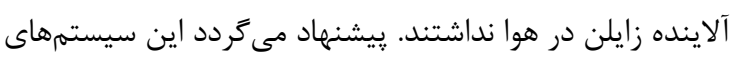

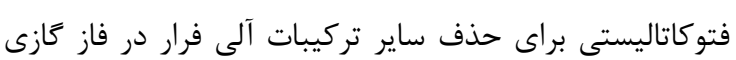

$$
\text { مورد استفاده قرار كيرند. }
$$

\section{تشكر و قلر هانى}

مطالعه حاضر از سوى حوزه معاونت يزوهشى دانشعاه علوم

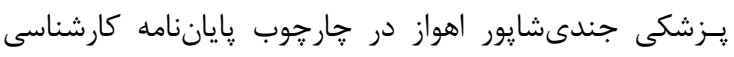
ارشد با شماره طرح ETRC-9604 حمايت مالى شده است إن. بدينوسيله از اين معاونت محترم تشكر و قدردانى مى

\section{REFERENCES}

1. Winder C, Stacey NH. Occupational toxicology. Florida: CRC press; 2004.

2. Xylene (Mixed Isomers). Petrochemical Transportation Engineering Co. (P.T.E.C.). Available at: URL: http:// www.ptec-ir.com/uploads/Xylene_(mixed_isomers) 685.pdf; 2018.

3. Moussavi GR, Khavanin A, Mokarami HR. Removal of Xylene from waste air stream using catalytic ozonation process. Iran J Health Environ. 2010;3(3):239-50.

4. Delage F, Pré P, Le Cloirec P. Mass transfer and warming during adsorption of high concentrations of VOCs on an activated carbon bed. Exper Theoretical Analysis. 2000;34(22):4816-21. DOI: 10.1021/es001187x
نتايج مطالعه حاضر نشان دادند كه در غلظت •ه بخش بر

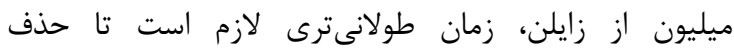

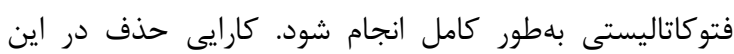

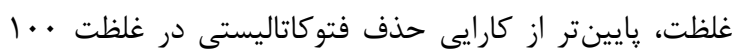
بخش بر ميليون مىباشد كه علت اين امر مىتواند كاهش ميزان

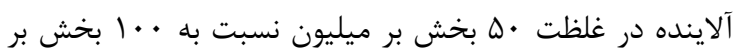

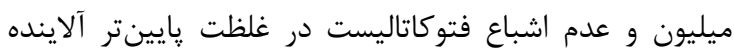

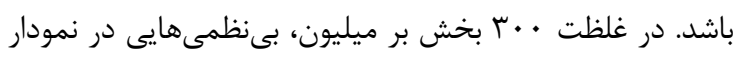

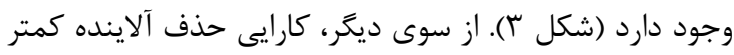

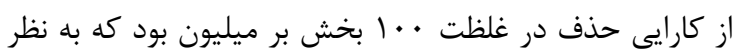

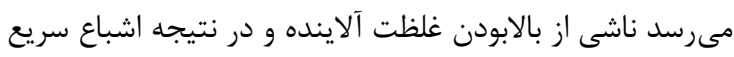

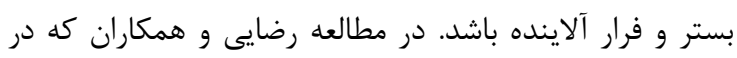

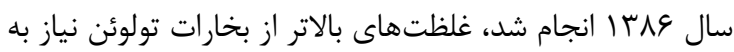

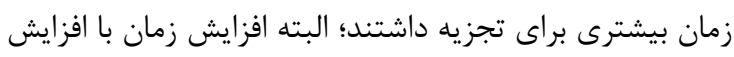

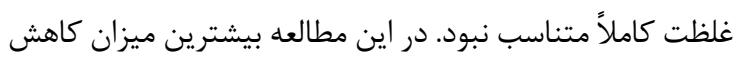
غلظت تولوئن مربوط به به كاركيرى همزمان UV-A از داخل داخل و

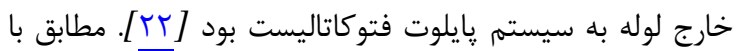

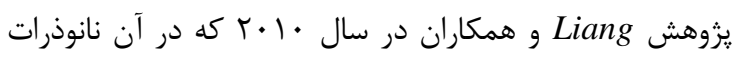

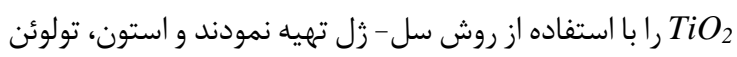

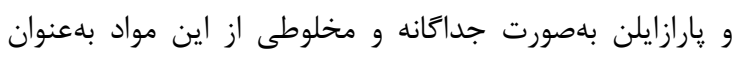
تركيبات آلى فرار براى حذف فتوكاتاليستى با استفاده از فيلم

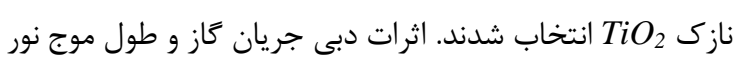

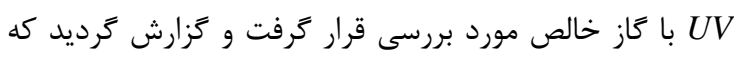

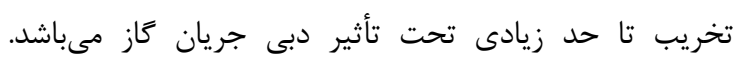

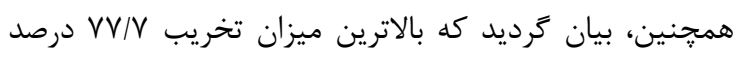

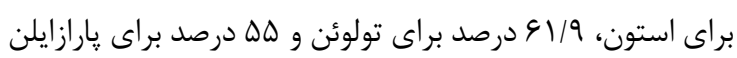

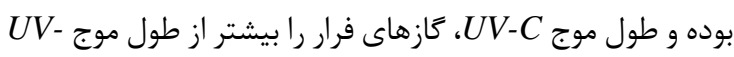

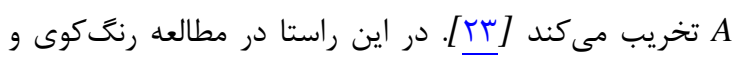

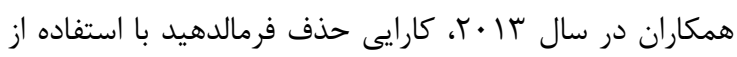

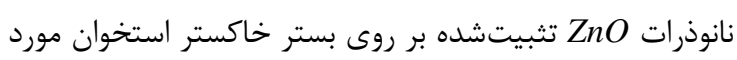

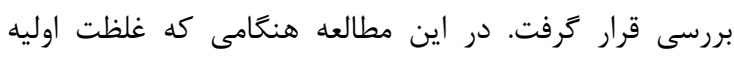

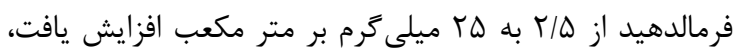
كارايى تجزيه فرمالدهيد از

5. Song W, Tondeur D, Luo L, Li J. VOC adsorption in circulating gas fluidized bed. Adsorption. 2005;11(1):853-8. DOI: $10.1007 /$ s10450-005-6035-z

6. Ochiai T, Fujishima A. Photoelectrochemical properties of TiO2 photocatalyst and its applications for environmental purification. J Photochem Photobiol. 2012;13(4):247-62. DOI: 10.1016/j.jphotochemrev.2012.07.001

7. Carp $O$, Huisman $C L$, Reller A. Photoinduced reactivity of titanium dioxide. Progr Solid State Chem. 2004;32(1-2):33177. DOI: 10.1016/j.progsolidstchem.2004.08.001

8. Komarneni $S$, Esquivel $S$, Noh YD, Sitthisang $S$, Tantirungrotechai J, Li H, et al. Novel synthesis of nanophase anatase under conventional-and microwave-hydrothermal 
conditions: DeNOx properties. Ceram Int. 2014;40(1):2097102. DOI: 10.1016/j.ceramint.2013.07.123

9. Mohamed RM, McKinney DL, Sigmund WM. Enhanced nanocatalysts. Mater Sci Eng R Rep. 2012;73(1):1-3. DOI: 10.1016/j.mser.2011.09.001

10. Hoffmann MR, Martin ST, Choi W, Bahnemann DW. Environmental applications of semiconductor photocatalysis. Chem Rev. 1995;95(1):69-96. DOI: 10.1021/cr00033a004

11. Son DY, Im JH, Kim HS, Park NG. $11 \%$ efficient perovskite solar cell based on $\mathrm{ZnO}$ nanorods: an effective charge collection system. J Phys Chem C. 2014;118(30):16567-73. DOI: $10.1021 / j p 412407 \mathrm{j}$

12. Fuku K, Wang N, Miseki $Y$, Funaki T, Sayama $K$. Photoelectrochemical reaction for the efficient production of hydrogen and high-value-added oxidation reagents. Chem Sus Chem. 2015;8(9):1593-600. PMID: 25872474 DOI: 10.1002/cssc. 201403463

13. Wang K, Shi Y, Dong Q, Li Y, Wang S, Yu X, et al. Lowtemperature and solution-processed amorphous WO $X$ as electron-selective layer for perovskite solar cells. J Phys Chem Lett. 2015;6(5):755-9. PMID: 26262648 DOI: 10.1021/acs.jpclett. 5 b00010

14. Chavadej S, Kiatubolpaiboon $W$, Rangsunvigit $P$, Sreethawong T. A combined multistage corona discharge and catalytic system for gaseous benzene removal. J Mol Catalysis A Chem. 2007;263(1):128-36. DOI: 10.1016/j. molcata.2006.08.061

15. Chen X, Burda C. The electronic origin of the visible-light absorption properties of $\mathrm{C}$-, $\mathrm{N}$-and $\mathrm{S}$-doped $\mathrm{TiO} 2$ nanomaterials. J Am Chem Soc. 2008;130(15):5018-9. PMID: 18361492 DOI: 10.1021/ja711023z

16. Markowska-Szczupak A, Ulfig K, Morawski AW. The application of titanium dioxide for deactivation of bioparticulates: an overview. Catalysis Today. 2011; 169(1):249-57. DOI: 10.1016/j.cattod.2010.11.055

17. Yu J, Jaroniec M, Xiao W, Trapalis C, Liu H. TiO2 photocatalytic materials 2014. Int J Photoenergy. 2015; 2015:786562. DOI: 10.1155/2015/786562

18. Çeçen $F$, Aktas $\ddot{O}$. Activated carbon for water and wastewater treatment: Integration of adsorption and biological treatment. New Jersey: John Wiley \& Sons; 2011.
19. Sun RD, Nakajima A, Watanabe I, Watanabe T, Hashimoto $K$. TiO 2-coated optical fiber bundles used as a photocatalytic filter for decomposition of gaseous organic compounds. $J$ Photochem Photobiol A Chem. 2000;136(1):111-6. DOI: 10.1016/S1010-6030(00)00330-0

20. Chen Y, Crittenden JC, Hackney S, Sutter L, Hand DW. Preparation of a novel TiO2-based $p-n$ junction nanotube photocatalyst. Environ Sci Technol. 2005;39(5):1201-8. PMID: 15787357

21. Matsunaga T, Tomoda $R$, Nakajima T, Nakamura $N$, Komine T. Continuous-sterilization system that uses photosemiconductor powders. Appl Environ Microbiol. 1988;54(6):1330-3. PMID: 3046487

22. Rezaee A, Khavanin A, Saraf Mamoori R, Hajizadeh E. Elimination of toluene by Application of ultraviolet irradiation on TiO2 nano particles photocatalyst. J Mil Med. 2007;9(3):217-22. [Persian]

23. Liang WJ, Li J, Jin YQ. Photocatalytic degradation of gaseous acetone, toluene, and p-xylene using a TiO2 thin film. J Environ Sci Health A Tox Hazard Subst Environ Eng. 2010;45(11):1384-90. PMID: 20665322 DOI: 10.1080/ 10934529.2010.500925

24. Rangkooy HA, Rezaee A, Khavanin A, Jafari AJ, Khoopaie $A R$. A Study on photocatalytic removal of formaldehyde from air using $\mathrm{ZnO}$ nanoparticles immobilized on bone char. Qom Univ Med Sci J. 2011;7(2):27-34. [Persian]

25. Irvani H, Shojaee-Farah Abady H, Shahryari M, Nakhaei Pour M. Evaluation of photocatalytic removal of styrene from air flow using $\mathrm{ZnO}$ nanoparticles immobilized on ZSM-5 zeolite. Iran J Health Environ. 2017:10(2):165-74. [Persian]

26. Baran W, Makowski A, Wardas $W$. The effect of UV radiation absorption of cationic and anionic dye solutions on their photocatalytic degradation in the presence $\mathrm{TiO} 2$. Dyes Pigments. 2008;76(1):226-30. DOI: 10.1016/j.dyepig. 2006.08.031

27. Ghodsian M, Ayati B, Ganjidoust H. Determination of optimum amounts of effective parameters in reactive dyes removal using photocatalytic reactions by immobilized TiO2 nano particles on concrete surface. Water Wastewater. 2013;24(3):45-53. [Persian] 